\title{
O PROJETO “CUIDANDO DO CUIDADOR”: A EXPERIÊNCIA DE EDUCAÇÃO PERMANENTE EM SAÚDE DO CENTRO DE SAÚDE ESCOLA DE BOTUCATU
}

\author{
THE PROJECT "CARING FOR THE CARER": THE EXPERIENCE OF PERMANENT \\ EDUCATION IN HEALTH CARE AT THE HEALTH CENTRE ESCOLA DE BOTUCATU
}

\author{
Antonio Pithon Cyrino 1 \\ Edy Nakamoto 2 \\ Geni Lobato Gentil Rollo 3 \\ Marta Andrade 4 \\ Paula Freire 5
}

Resumo A experiência aqui relatada nasce de crises e tensões presentes no cotidiano de trabalho de um serviço de atenção primária à saúde. Surge, também, do esforço em transformar esse conflito em 'cuidado' dirigido ao conjunto da equipe. Para tanto, duas vivências que se estruturam para responder a tais desafios conformaram um projeto mais amplo de educação permanente em saúde, o "Cuidando do cuidador". Essa iniciativa buscou mobilizar e fazer circular valores e sentimentos que, usualmente, são pouco considerados em processos de educação no trabalho. Ao dar visibilidade a estas dimensões intersubjetivas, foi possível tornar presentes questões essenciais para pensar o papel de cuidador de que deve estar investido o profissional de saúde. Com o uso de recursos sociodramáticos em diferentes espaços do projeto, viabilizouse, ainda, um movimento de sensibilização que se inicia no profissional e sua identidade como pessoa, passa pelo reconhecimento do outro (colega de trabalho e paciente) e chega a um coletivo mais amplo, o institucional. O desenvolvimento do projeto ajudou a entender que a humanização de nossos serviços exige, igualmente, reconhecer que nós, cuidadores, também somos frágeis e humanos.

Palavras-chave educação permanente em saúde; humanização; relação profissional de saúdepaciente; cuidado em saúde.
Abstract The experience narrated here had its origin in the crises and tensions present in the everyday work of a basic health care unit. It was also the result of an effort to change conflict into "care" for the entire team. For this purpose, two practices that were structured to respond to these challenges gave origin to a wider project in permanent health education, called "Caring for the Carer". This initiative attempted to encourage and propagate values and feelings that are normally ignored in processes of education at work. By giving visibility to these inter-subjective dimensions, it was possible to bring to light some essential issues related to the role of carer that should be assumed by the health professional. With the help of socio-dramatic resources in different areas of the project, we also generated a sensitization movement that begins with the professional and his/her identity as a person, includes the recognition of the Other (colleague and patient) and reaches a wider collective, i.e. the institutional one. The project development helped us to understand that the humanization of our services requires the recognition that we, carers, are also human and fragile. Key words permanent education in health; humanization; relationship health professional-patient; health care. 
O homem está apto ao encontro na medida em que ele é totalidade que age.

Martin Buber

\section{Introdução}

Relatar uma experiência é sempre uma oportunidade de reflexão sobre processos construídos na correria cotidiana do trabalho, que poucas vezes nos permite escrever sobre o vivido. Este texto é fruto de uma etapa inicial de sistematização que nos possibilitou, especialmente, reconhecer questões geradoras e o contexto em que se instituiu esse processo, descrever as estratégias de ação adotadas em seu desenvolvimento e, por fim, interpretar algumas expressões que tal processo assumiu para os profissionais envolvidos.

Dentre as diferentes possibilidades de entender 'sistematização de uma experiência', a tomamos aqui como um "processo permanente de reflexão e acumulativo de produção de conhecimento a partir de experiências de intervenção em uma realidade social“ (Barnechea, Gonzalez e Morgan, 1998, p.1). É especialmente uma "reconstrução e reflexão analítica sobre uma experiência vivida, mediante a qual interpretamos o sucedido para melhor compreendê-lo" (Marfil e Morgan, 1995, p. 12).

Assim como a experiência aqui apresentada foi produção de um coletivo pensante e criativo, a vivência de sistematizá-la foi, também, momento de criação e reflexão e, principalmente, de redescoberta de suas possibilidades. E resultou de múltiplas e distintas respostas que equipes de trabalho de um serviço de atenção primária à saúde construíram no enfrentamento de suas dificuldades de operação do trabalho. Estas vivências têm um eixo comum em torno da integração dos trabalhos de atenção e, ainda, daquelas manifestas na complexa relação entre os profissionais de saúde e usuários do serviço.

Tais vivências mostraram-se relevantes e significativas para as equipes e, por isso, desaguaram num leito mais caudaloso, ao qual chamamos projeto "Cuidando do cuidador". O desenvolvimento deste projeto nos permitiu tratá-lo, ainda que ex post, como uma iniciativa de 'educação permanente em saúde' (EPS), ao reconhecermos ser esta "toda proposta educativa realizada no âmbito laboral, voltada à reflexão e intervenção sobre o processo de trabalho, de modo a aprimorar a qualidade do serviço e as condições de trabalho", o que significa pensar a "educação no trabalho, pelo trabalho e para o trabalho" (Rovere, 1994, p. 64). Esta concepção nos faz perceber que a EPS não se reduz a atividades ou programas de capacitação ou formação aplicada ao setor saúde, mas pode ser "considerada como intervenção capaz de mobilizar, circular, produzir e transferir conhecimento, tecnologia, valores e sentimentos" (Rovere, 1994, p. 65). Em nosso projeto, especialmente 
estas duas últimas dimensões — valores e sentimentos — foram elementos de destaque.

Na sistematização produzida nos foi possível perceber diversos pressupostos subjacentes ao conjunto de vivências e ao projeto "Cuidando do cuidador", como expressão de conjunto, que poderíamos sintetizar na necessidade de humanizar nossos serviços de saúde enfrentando a alienação no trabalho.

Este é um enorme desafio para as instituições do Sistema Único de Saúde (SUS): humanizar as relações entre profissionais de saúde e usuários dos serviços. O Ministério da Saúde, em documento recente, em que expõe a sua "Política Nacional de Humanização", reconhece que "um dos aspectos que mais tem chamado a atenção, quando da avaliação dos serviços, é o despreparo dos profissionais para lidar com a dimensão subjetiva que toda prática de saúde supõe" (MS, 2003, p.6).

Produzir essa relação humanizada exige, de partida, alcançar uma sensibilidade do profissional para com o sofrimento do outro, de seu paciente. O que parece tarefa simples é, na verdade, complexa, se considerarmos as bases dominantes da biomedicina, na qual somos formados para atuar mais sobre o corpo do que com a pessoa.

O tema da humanização nos aproxima de questões ético-filosóficas produzidas, mais recentemente, sobre o 'cuidado'. Uma das expressivas contribuições sobre a temática nos é trazida por Ayres (2001, p.71), deslocando o enfoque da categoria trabalho ao afirmar que "cuidar da saúde é mais que construir um objeto e intervir sobre ele. Para cuidar, há que se (...) construir projetos (...) e sustentar, ao longo do tempo, uma certa relação entre a matéria e o espírito, o corpo e a mente (...), moldados a partir de uma forma que o sujeito quer opor à dissolução (...) de sua presença no mundo". Portanto, o cuidado não se reduz ao tratar e não deve ser visto como um atributo de uma só categoria profissional, mas como atitude necessária a todas as formas de trabalho em saúde (Nogueira, 2002).

Muitas são as questões postas para se pensar a reorganização das práticas de saúde, nessa perspectiva do cuidado. Ayres (2004) destaca três fundamentais para operar uma verdadeira reconstrução de nossas práticas de atenção: o voltar-se à presença do outro, a otimização das interações e a ampliação e enriquecimento dos horizontes que orientam os âmbitos e os agentes das práticas. As dimensões propostas reforçam muito do que trabalhamos no projeto em foco, ainda que, muitas vezes, não as percebêssemos com a clareza e a riqueza com que nos brinda Ayres, especialmente pelos caminhos, pouco explorados, que abre à reflexão.

Dentre outras possíveis conexões com campos do conhecimento e de práticas, cabe reconhecer outros aportes que se mostram extremamente produtivos para operar mudanças voltadas para essa humanização das práticas 
(Franco, Bueno e Merhy, 1999; Teixeira, 2003), todavia fogem aos objetivos deste texto tratá-los.

\section{O Centro de Saúde Escola de Botucatu}

A experiência foi desenvolvida no Centro de Saúde Escola de Botucatu (CSE): unidade da Faculdade de Medicina de Botucatu (FMB), da Universidade Estadual Paulista (Unesp), de ensino, pesquisa e atenção primária à saúde, vinculada ao Departamento de Saúde Pública. Atualmente, o CSE é responsável pela assistência à saúde de aproximadamente 30.000 habitantes do município de Botucatu ( $25 \%$ da população local), prestada em duas unidades (Vila dos Lavradores e Vila Ferroviária), por meio dos Programas de Atenção à Criança e Adolescente, à Mulher, ao Adulto e no Envelhecimento. Oferece, ainda, assistência em Saúde Mental, Saúde Ocupacional, Saúde Ocular, Fonoaudiologia, Acupuntura e Homeopatia. A instituição tem um total de 82 servidores de diferentes categorias profissionais, com distintos vínculos empregatícios, predominando aquele com a FMB-Unesp (e Fundação a ela vinculada).

Desde sua instalação em 1972, dentro dos marcos do movimento da Medicina Comunitária, o CSE buscou organizar um modo de operar o trabalho de atenção à saúde com base em alguns dos princípios incorporados, décadas mais tarde, ao SUS, como a integralidade da atenção e a regionalização da assistência. Foi, nessa perspectiva, que, em seus primeiros anos de atividade, desenvolveu um modo de organização do trabalho - a "Programação em Saúde" —, que foi adotado e extensivamente implantado, nessa época, pela Secretaria de Estado da Saúde de São Paulo, nos então recém-estruturados Centros de Saúde (Cyrino, 1993; Cyrino e Schraiber, 2002).

O processo aqui apresentado teve início em 1999, em um contexto de mudança institucional, direcionada para a retomada de sua finalidade de produção e inovação tecnológica, em que foi essencial valorizar a capacidade de criação e crítica da equipe sobre a prática assistencial e de gestão.

O desejo de instituir um novo patamar ético-político de relação interprofissional, bem como o de assegurar uma cultura institucional de inovação, nos levou a estruturar, progressivamente, um modo de organização do trabalho gerencial mais participativo (ou de co-gestão). Nesse processo, incorporou-se o planejamento estratégico como opção técnico-política, reconhecendo-o como potente tecnologia para viabilizar mudanças, sem desconhecer suas limitações frente ao conjunto de tarefas de um sistema de gestão (Campos, 1998). Para tanto, estruturou-se um desenho organizacional que assegurasse a participação da equipe e estimulasse a autonomia - elementos valiosos para facilitar processos criativos. 
A prática vivenciada de planejamento e gestão permitiu, progressivamente, dispor de uma estrutura com mais autonomia para cada equipe de trabalho, sem reduzir o compromisso dessas equipes multiprofissionais com a missão e os objetivos institucionais. Isso foi assegurado, em parte, pela formação de um colegiado de gestão, com a representação das distintas equipes, nas quais se incluem as áreas de atenção, anteriormente citadas: Criança, Adulto etc. As equipes de cada uma dessas áreas de trabalho, por sua vez, passaram a organizar-se internamente com uma coordenação e reuniões regulares de equipe, em que se combinou a discussão técnica6, especialmente sobre a organização da atenção à saúde, com aquela de gestão do cotidiano do trabalho (Cyrino et al., 2001).

A criação desses espaços de planejamento e gestão foi fundamental para uma vivência mais reflexiva e criativa no trabalho, com novas produções das equipes, num movimento progressivo de crescimento individual e coletivo.

Diversas outras vivências podem ter contribuído para a realização do projeto "Cuidando do cuidador", dentre elas, caberia destacar o projeto "Arte e Saúde", pelo enriquecimento e ampliação de horizontes trazidos ao abrirmos os espaços institucionais a interações com outras linguagens, como a da expressão artística (Cyrino, 2001; Cyrino et al., 2003).

A experiência que relatamos, a seguir, se apenas foi possível em função de um novo contexto institucional, também contribuiu para este processo de mudança, já que auxiliou os agentes dessa instituição a buscarem outros caminhos para lidar com problemas que nos submetem e enfraquecem como profissionais de saúde e, antes de tudo, como pessoas.

\section{O projeto "Cuidando do cuidador": do conflito ao cuidado}

O projeto "Cuidando do cuidador" constituiu-se a partir da confluência de duas experiências que tiveram em comum a presença de usuários portadores de sofrimento mental e seus cuidadores, profissionais de saúde de distintas áreas de atenção. Como o Centro de Saúde Escola não se trata de um serviço especializado em atenção à saúde mental, mas de um serviço de atenção primária à saúde, a presença do portador de doença mental ou de um sofrimento mental cria um campo, às vezes, permeado de tensões decorrentes da presença daquele que é 'diferente'. Por outro lado, é por meio da percepção e reflexão sobre tais problemas que emergem ricas oportunidades de lidar com valores e sentimentos nem sempre passíveis de expressão no dia-a-dia do trabalho. É na presença dessas dimensões mais subjetivas, ou intersubjetivas, dos profissionais que podemos arriscar caminhos que abrem a possibilidade de uma atenção mais integral e humana. Descobrimos isso enfrentando problemas decorrentes da presença desses usuários e de nós, seus cuidadores. 
A primeira dessas experiências deu-se na área de "Atenção à Saúde do Adulto". O diagnóstico não era novo: a dificuldade dos clínicos para lidarem com o sofrimento mental de seus pacientes. Este problema se apresentou, muitas vezes, quando o encaminhamento do clínico à área de "Atenção à Saúde Mental" era feito sem que os pacientes soubessem o motivo, o que dificultava sua participação nas propostas terapêuticas dessa área de assistência, quando não a impedia totalmente.

Da dificuldade de comunicação entre estas áreas nasceu a oportunidade do encontro. Para os médicos clínicos, tal articulação deveria construir-se mediante um programa de capacitação com temas de saúde mental, como inicialmente realizado. Todavia, o processo tomou outra direção após os primeiros encontros: conformou-se um espaço de reunião mensal, primeiramente com médicos, que logo se ampliou para o conjunto dos profissionais de saúde da área de adulto, com a coordenação de uma psicóloga da equipe de saúde mental. O objetivo deste grupo foi o de estabelecer um lugar para falar das relações entre os próprios membros da equipe, e destes com a instituição e seus pacientes.

O segundo processo deu-se a partir de uma crise deflagrada por um paciente psicótico que agrediu uma funcionária, criou vários outros confrontos, o que gerou um clima de medo e insegurança. Esse acontecimento pôs em colapso os limites, inclusive físicos, dos profissionais do serviço. Paradoxalmente, a expressão dessa fragilidade trouxe também, por parte da equipe, a percepção da necessidade de buscar caminhos que não fossem aqueles da exclusão do diferente.

A equipe de saúde mental propôs que se criasse um espaço de participação de todos os funcionários na busca de uma abordagem coletiva do problema. Para tanto, iniciamos, em 20007, encontros trimestrais com a participação do conjunto da equipe da unidade, coordenados por psicodramatistas externos. Durante o período das reuniões (aproximadamente quatro horas), o atendimento ao público era suspenso para assegurar a participação de todos os servidores. O colegiado de gestão, com a participação da equipe de saúde mental, discutia os encontros realizados e definia a continuidade do processo e as estratégias de dinâmica grupal mais adequadas.

A expressão dominante dos primeiros encontros foi a da necessidade do cuidado com aquele que faz o papel de cuidador, suas disponibilidades e limites. Isto ocorreu porque a equipe se fez protagonista desse carecimento, numa evidente inversão de papéis. Isso se evidencia no discurso dos próprios participantes:

“Acho que [esse projeto] é uma coisa muito importante, porque quem cuida de pessoas doentes fica também adoentada - fica com dó, envolvida, fica triste tem que ter quem cuide da gente. É trabalhar o próprio sentimento da gente, em 
casa, no serviço... porque a gente sofre. Às vezes, por coisa boba" (auxiliar de enfermagem 3).

"Para mim, é um espaço onde as pessoas têm grande chance de trabalhar com os sentimentos... é claro que com sentimentos do profissional. Porque, muitas vezes, não é possível esta separação. O que o trabalho nos atinge emocionalmente e como lidar com isto" (enfermeira 1).

Foi, portanto, nesse lugar de encontro que tivemos a possibilidade conjunta de perceber que não éramos os profissionais de saúde obrigados a tudo resolver. O mito da onipotência do 'cuidador' se desfaz quando nos vemos sendo cuidados. A introdução do recurso sociodramático, na vivência coletiva, possibilitou a colocação em cena das intersubjetividades, à medida que, postos a conversar sobre nossas relações de trabalho e nossas fragilidades, na condição de cuidadores, descobrimo-nos humanos e, às vezes, despreparados.

O compartilhamento da experiência trouxe-nos, ainda, a possibilidade da reflexão crítica, da solidariedade e da co-responsabilidade grupal. Como no psicodrama “os membros do grupo são levados, progressivamente, em momentos oportunos durante (...) [esse processo], a compreender sua responsabilidade recíproca e se conduzir conseqüentemente" (Moreno, 1974, p. 24).

Com isso, tornou-se possível, sobretudo, a visibilidade da pessoa dos profissionais e de reconhecimento do outro. Estimulados à atuação espontânea, dentro do contexto sociodramático, revelaram-se facetas do grupo, até então, desconhecidas, restritos que estavam ao desempenho do papel conservado. Novos vínculos são estabelecidos, a percepção de si e do outro se torna mais 'real', e as comunicações passam a fluir de maneira mais leve e produtiva. Ass características dessas vivências estão presentes nos discursos de diferentes profissionais convidados a falar a respeito:

\footnotetext{
“Só ter o espaço... para você pôr as suas coisas e o outro respeitar e entender o seu sofrimento. Tem hora que não precisa nem falar, só de olhar já percebe. Tem hora que você chora, bom... eu já chorei, já dei risada" (auxiliar de enfermagem 3).

"Pelo emocional... a gente sai dali um pouco mais aliviado de saber que tem alguém que vai saber o que a gente sente. Cada um pode se colocar no lugar do outro e saber o que cada um pensa" (auxiliar de enfermagem 2).
}

Quando o grupo fica autorizado a percorrer o trajeto da onipotência à impotência, vai se construindo o lugar das afinidades, da força das parcerias, da possibilidade e liberdade de expressão, e da confiança de poder ser. Alguns discursos explicitam uma potencial capacidade para esse trabalho em 
estimular a participação, ao incluir as subjetividades, não na direção de uma 'psicologização', mas no sentido de uma possível desalienação no trabalho:

"Este trabalho faz a gente falar o que se pensa... que não ia falar. A gente vai ficando bocudinha" (auxiliar de enfermagem 1).

“É um local onde a gente pode desabafar, resolver problemas com colegas da área" (médica 2).

Foi no desenrolar desse processo que se verificou a necessidade de estruturação do projeto "Cuidando do cuidador", na medida em que reconhecemos que reuniões regulares, com grupos menores, seriam essenciais para garantir a estabilidade dos vínculos interprofissionais, bem como assegurar uma participação mais contínua de cada um e das equipes, dando mais condições de promover a recriação dos papéis em outra perspectiva, talvez, mais humana.

"Foi importante pra eu me soltar, eu acho que eu melhorei 80\%, sempre fui muito calada e hoje eu consigo botar pra fora o que eu penso" (auxiliar de enfermagem 2).

"Lá eu consigo analisar o serviço um pouco de fora, e aí aquela angústia, aquela coisa ruim que a gente sente em algumas situações do dia-a-dia, passa" (médica 1).

De modo geral, neste processo, constatamos, de um lado, um movimento que se inicia no profissional, em sua identidade como pessoa, passa pelo reconhecimento do grupo e chega a um coletivo mais amplo, o institucional; de outro, as 'categorias profissionais' tendem a tornar-se secundárias. As pessoas, igualadas no compartilhamento do que é subjetivo, podem colocarse, ao mesmo tempo, a serviço e aos cuidados do grupo e da instituição.

Vivenciar, no espaço autorizado, uma percepção diferente da composição dos poderes e fragilidades encorajou a equipe a ampliar a temática do cuidado para as necessidades de cada área de trabalho e daquela da instituição como um todo. Apropriando-se do serviço, passaram a se preparar e organizar a transição que se iniciava com a mudança da diretoria da instituição. De certo modo, foi possível nesse processo, por meio do psicodrama, que cada um experimentasse e confrontasse as próprias expectativas com as do grupo, assim vivenciando os conflitos no papel e, ao final, podendo fazer a conciliação entre a prática e o que ela pode vir a ser. Esse exercício pôde remeter o profissional de volta ao seu cotidiano mais bem instrumentalizado para promover mudança: 
“[É um] espaço dentro do serviço para cuidar de nossa saúde mental e pensar também que caminho o serviço está tomando, que caminho a gente está escolhendo para o serviço tomar. Espaço em que as pessoas estão unidas sem o atropelo do dia-a-dia" (médica 1).

A estruturação do projeto "Cuidando do cuidador" abriu a possibilidade de ampliar o trabalho, que já era feito na área de Saúde do Adulto, para outras equipes multiprofissionais que estivessem dispostas a partilhar essa vivência, o que ocorreu, algum tempo depois, com a equipe de Saúde da Criança e a da Unidade da Vila Ferroviária.

A equipe que passou a coordenar o projeto reconheceu, também, a necessidade de criar um espaço de encontro específico para a categoria profissional dos auxiliares de enfermagem, ainda que os mesmos continuassem participando do projeto junto às outras equipes das distintas áreas de trabalho. Tal iniciativa logo se mostrou muito adequada, dada a enorme tensão vivida por esses trabalhadores no dia-a-dia, colocados entre a pressão da demanda dos usuários dos serviços, de um lado, e as restrições de oferta, de outro. Uma mudança percebida, entre os auxiliares de enfermagem, foi a expressão de opiniões, críticas e sentimentos que dificilmente seriam manifestados diante do conjunto dos profissionais, incluindo outras categorias, vistos como autoridades de algum saber ou poder.

Os encontros realizados nessas áreas assistenciais, que continuam acontecendo até hoje, têm se desenvolvido de maneira diversificada, na medida em que dependem, essencialmente, das questões postas pelos próprios grupos. Duram de duas a três horas, acontecem com periodicidade mensal e são coordenados por diferentes membros da equipe de Saúde Mental, que assumem o papel de supervisor.

Cabe destacar algumas questões relacionadas a quem é esse supervisor, sua função e limites do papel. Dada a restrição de recursos para dispor de supervisor externo para realizar o conjunto do trabalho junto às equipes, houve o envolvimento de duas psicólogas e uma psiquiatra da própria equipe nesta supervisão, além da participação de um supervisor externo. Para realizar essa proposta, os supervisores (membros da equipe) enfrentam a tensão entre ser parte dessa equipe e, ao mesmo tempo, se colocar como um terceiro, um olhar 'de fora' do grupo, para ajudá-los a se verem. É uma função de tradução, interpretação e sustentação de expressão das emoções. As equipes têm esperado desses supervisores que as ajudem na facilitação do trabalho grupal, especialmente, que as apóiem para atravessar os momentos de explicitação dos conflitos.

Para que o leitor possa ter uma idéia da dinâmica desses encontros, trazemos, a seguir, alguns momentos do projeto junto à equipe de Saúde da Criança. 
As reuniões do "Cuidando do cuidador", com a equipe da Saúde da Criança, vêm acontecendo desde outubro de 2001, com regularidade mensal e coordenadas por uma das psicólogas do CSE.

A equipe é constituída por três pediatras (um homem e duas mulheres), uma enfermeira, duas auxiliares de enfermagem e uma fonoaudióloga. Com exceção de uma das pediatras, mais nova na equipe e trabalhando 20 horas, os demais são contratados por 40 horas semanais e estão na equipe há mais de dez anos.

Trata-se de uma equipe, bem constituída e articulada, que tem a iniciativa de propor e executar diretrizes da atenção primária à criança na unidade básica, bem como articular essa atenção à supervisão de estágio de alunos de graduação de Medicina e médicos-residentes de distintos programas. Uma característica importante da equipe é o esforço para equilibrar a sempre crescente demanda com a qualidade da atenção e os recursos disponíveis. Esse tema é, freqüentemente, levado ao "Cuidando do cuidador": o sofrimento pelo medo da perda desse equilíbrio, da ruptura das conquistas até ali alcançadas no padrão de qualidade da atenção e perda de qualidade de vida pessoal.

Uma das auxiliares de enfermagem compartilhou com o grupo estar tendo insônia, ficar pensando excessivamente no trabalho, pensamento este que invadia outros aspectos de sua vida. O médico queixou-se de azia, associada ao horário de almoço sempre postergado e às pressas.

Num dos encontros, a equipe foi solicitada a montar uma imagem desse "medo da perda do equilíbrio". Uma das auxiliares de enfermagem construiu uma passagem estreita na sala, por onde deveriam passar todos ao mesmo tempo. Ao dar movimento a essa imagem, sentiu-se mal com a 'explosão' ali encenada. Em seguida, o grupo foi solicitado a recriar a imagem, e o fez para que não houvesse a tal explosão, e conversou sobre as medidas práticas a tomar no cotidiano do trabalho.

Importante mencionar, no recorte de temas, o compartilhar sentimentos sobre a perda de cliente. Uma das pediatras queixou-se da perda de uma cliente com câncer e da dificuldade de lidar com os sentimentos de revolta da mãe, inconformada porque tinha grande esperança de cura, já que a filha se mostrara bem até então, participante, alegre e cheia de vida. Embora a criança fosse acompanhada pelo setor de oncologia do hospital, a mãe mantinha contatos freqüentes com a equipe, pois trazia a criança para ser avaliada sempre que surgia algum sintoma novo. Falar sobre isso fez com que a auxiliar de enfermagem, que também acompanhava essa criança, se expressasse. Ambas choraram e se declararam surpresas com o que aflorou de sentimento. Como efeito dessa troca, a pediatra pôde oferecer à mãe um espaço de escuta e sustentar essa oferta quando ela a procurou, tempos depois, para conversar, com fotos da criança. 
Tal compartilhar não aconteceu quando o pediatra perdeu um cliente que acompanhou, cuidadosamente, nos dias e eventos antecedentes ao falecimento. A morte do menino se deu por complicações inesperadas no hospital para o qual ele o havia encaminhado. Embora o pediatra tivesse tomado todos os cuidados necessários, os pais projetaram sobre ele sua raiva e inconformidade diante da perda. Foi uma situação geradora de sofrimento para o pediatra. Por que o tema não apareceu nesses encontros?

O episódio revela que a transferência, o que cada um pode esperar desse espaço, é singular e essa expectativa necessita ser elaborada, revista e continuamente atualizada no grupo para que não se perca o potencial de cuidados.

\section{Conclusão}

À guisa de conclusão, podemos dizer que a consolidação do projeto "Cuidando do cuidador" deu-lhe a característica de um trabalho de educação permanente em saúde, visto que, diante dos conflitos cotidianos, pudemos explicitá-los e enfrentá-los, fazendo emergir, mobilizar e circular valores e sentimentos no interior do serviço. Foi possível, também, trocar saberes, ao partilharmos espaços em que foi sendo admissível uma certa horizontalização das relações e a percepção de que "todo mundo sabe alguma coisa e ninguém sabe tudo" (Costa, 2003, p.1). O espaço conquistado para a reflexão permanente sobre a prática e os relacionamentos, o novo olhar, que inclui as subjetividades no cotidiano dos trabalhadores do serviço, estimulam a mobilidade nos papéis institucionais e a construção, a cada momento, de novos acordos dentro da equipe.

Ao trazermos a vivência do projeto, não o fazemos como exposição de um modelo de educação permanente que tenha destacado as dimensões da intersubjetividade da equipe, mas como convite à reflexão de que o caminho para a humanização de nossas instituições passa pelo reconhecimento de que nós, cuidadores, também somos frágeis. Talvez este seja um passo a mais para tornar possível um cuidado cada vez mais humano para os usuários de nossos serviços de saúde. 


\section{Agradecimentos}

Os autores agradecem aos psicodramatistas José Roberto Tozoni Reis e Rosilda Antônio, que colaboraram em diferentes momentos do projeto, e aos membros do colegiado de gestão que participaram da elaboração do projeto "Cuidando do cuidador" e que continuam a sustentar com entusiasmo sua viabilidade junto às suas equipes.

\section{Notas}

1 Professor do Departamento de Saúde Pública da Faculdade de Medicina de Botucatu (Unesp). Médico sanitarista, mestre e doutorando em Medicina Preventiva pela Faculdade de Medicina da USP. <acyrino@fmb.unesp.br>

2 Médica psiquiatra do Centro de Saúde Escola da Faculdade de Medicina de Botucatu-Unesp (CSE-FMB-Unesp), com especialização em Saúde Pública e formação em Psicodrama.<edyshi@uol.com.br>

3 Psicoterapeuta do CSE-FMB-Unesp. Psicóloga com especialização em Psicodrama e Gestalterapia.<hrollo@uol.com.br>

4 Psicoterapeuta do CSE-FMB-Unesp. Psicóloga com especialização em Psicodrama. <kakabot@bol.com.br>

5 Assessora do CSE-FMB-Unesp, psicóloga e psicoterapeuta, com especialização em Psicodrama. <freire@lpnet.com.br>

6 Como parte da estruturação de um programa de educação permanente, foram criados, em cada área assistencial, mais dois espaços regulares de educação permanente: a reunião clínica (para discussão, em equipe, de casos atendidos, com a participação de profissionais da área de saúde mental) e a reunião temática (em geral, com convidados externos e aberta a profissionais de outros serviços regionais).

7 Esse processo, com os mesmos objetivos e metodologia, estendeu-se até 2002.

8 Os depoimentos foram tomados de diferentes profissionais, em 2003. Aqui, estes são identificados apenas pelas categorias profissionais, adotando-se uma numeração com o intuito de preservar a identidade das pessoas. 


\section{Referências}

AYRES, José Ricardo de C. 2001. Sujeito, intersubjetividades e práticas de saúde. $\mathrm{Ci}$ ência e Saúde Coletiva, v. 6, n. 1, p. 63-72.

AYRES, José Ricardo de C. 2004. Cuidado e reconstrução das práticas de saúde. Interface: Comunicação, Saúde, Educação, v. 8, n. 14, p. 73-91.

BARNECHEA, Maria M.; GONZALEZ, Estela; MORGAN, Maria L. 1998. La producción de conocimientos en sistematización. Lima, 1998. (Ponencia presentada al Seminario Latinoamericano de Sistematización de Prácticas de Animación Sociocultural y Participación Ciudadana en América Latina. Medellín, Colombia, ago. 1998). Disponível em: <http://www. fondominkachorlavi.org/concurso2003/ docs/.PDF> Acesso em: 25 mar. 2003.

CAMPOS, Gastão W. S. 1998. Cadernos de Saúde Pública, v. 14, n. 4, p. 863-870.

CostA, Rogério. s/d A cartografia dos saberes: a sinergia das inteligências e a partilha dos conhecimentos. Disponível em: $<$ http://www.ddic.com.br/texts/lib_car tsabe.htm>. Acesso em: 1 abr. 2003.

CYRINO, Antonio Pithon. 1993. Organização tecnológica do trabalho na reforma das práticas e dos serviços de saúde: estudo de um serviço de atenção primária à saúde. Dissertação de Mestrado, São Paulo: Faculdade de Medicina, Universidade de São Paulo.

2001. Arte, muitos são os sentidos. Interface: Comunicação, Saúde, Educação, v. 5, n. 8, p. 157-157.

. et al. 2001. Planejamento e gestão de unidades de saúde: a experiência do Centro de Saúde Escola de Botucatu. Olho Mágico, v. 9, n. 1, p.100-101.

; SCHRAIBER, Lilia B. 2002. O projeto Centro de Saúde Escola em ação e os impasses do cotidiano. In: CYRINO, A. P. \& MAGALDI, C. (orgs.) Saúde e comunidade: 30 anos de experiência de extensão universitária em Saúde Coletiva. Botucatu, S.P.: Faculdade de Medicina de Botucatu/Comissão Editorial, Cultura Acadêmica Editora, p. 67-124.

et al. 2003. Arquitetura, arte e saúde: a transformação do espaço numa instituição de saúde. Ciência e Saúde Coletiva, v. 8 (s.1), p. 158.

FRANCKE, Marfil; MORGAN, María de la Luz. 1995. La sistematización: apuesta por la generación de conocimientos a partir de las experiencias de promoción. Escuela para el desarollo (Materiales didácticos n.1). Disponível em: < http:// www.fondominkachorlavi.org/concurso2003/docs/marfilfranke.PDF>. Acesso em: 25 abr. 2003.

FRANCO, Túlio. B; BUENO, Wanderley S.; MERHY, Emerson E. 1999. O acolhimento e os processos de trabalho em saúde: o caso de Betim, Minas Gerais, Brasil. Cadernos de Saúde Pública, v. 5, n. 2, p. 345-53.

MORENO, Jacob L. 1974. Psicoterapia de grupo e psicodrama: introdução à teoria e à prática. São Paulo: Mestre Jou.

MS (Ministério da Saúde). 2003. HumanizaSUS: Politica Nacional de Humanização. Série B. Textos Básicos de Saúde. Brasília: Editora MS.

NOGUEIRA, Roberto P. 2002. O trabalho em saúde hoje. In: NEGRI, Barjas et al. (orgs.) Recursos humanos em saúde: politica, desenvolvimento e mercado de trabalho. Campinas: Unicamp, Instituto de Economia, p. 255-273.

ROVERE, Mario R. 1994. Gestión estratégica de la educación permanente en salud. In: HADAD, Q., J.; ROSCHKE, M. A. C.; DAVINI, M. C. (eds.) Educación permanente de personal de salud. Série Desarrollo de Recursos Humanos, n.100. OPS: Washington, D.C, p. 63-106.

TEIXEIRA, Ricardo R. 2003. O acolhimento num serviço de saúde entendido como uma rede de conversações. In: PINHEIRO, Roseni; MATTOS, Ruben A. (orgs.) Construção da integralidade: cotidiano, saberes e práticas em saúde. Rio de Janeiro: Uerj, IMS, Abrasco, p. 89-111.

Recebido em 10/02/2004

Aprovado em 23/06/2004 